\title{
Assessment of the right ventricle by magnetic resonance imaging in chronic obstructive lung disease
}

\author{
L W Turnbull, J P Ridgway, W Biernacki, H McRitchie, A L Muir, J J K Best, \\ W MacNee
}

\begin{abstract}
Right ventricular wall and chamber volume were measured by magnetic resonance imaging in 16 patients with stable chronic obstructive lung disease who subsequently underwent measurement of pulmonary haemodynamics by right heart catheterisation. The patients had a forced expiratory volume in one second of 0.7 (SD 0.3 ) litres, a forced vital capacity of $2 \cdot 4(1.0) 1$, an arterial oxygen tension $\left(\mathrm{PaO}_{2}\right)$ of $6.5(1.3)$ $\mathrm{kPa}$, an arterial carbon dioxide tension $\left(\mathrm{PaCO}_{2}\right)$ of $6.5(1.0) \mathrm{kPa}$, and a mean pulmonary arterial pressure $30(10) \mathrm{mm}$ Hg. The mean right ventricular free wall volume was $57 \cdot 1(22.6) \mathrm{cm}^{3}$, compared with a mean value of $115.0(44 \cdot 3) \mathrm{cm}^{3}$ for the left ventricle and interventricular septal volume. The right ventricular chamber volume at end systole was $\mathbf{4 4 . 8}$ (23.4) $\mathrm{cm}^{3}$, whereas the left ventricular end systolic chamber volume was $51 \cdot 1$ $(35 \cdot 1) \mathrm{cm}^{3}$. The right ventricular free wall volume correlated with the right ventricular chamber volume $(r=0.71)$, systolic $(r=0.74)$ and mean $(r=0.72)$ pulmonary arterial pressure, pulmonary vascular resistance $(r=0.67)$, and $\mathrm{PaCO}_{2}$ $(r=0.56)$. There was no significant correlation between the right ventricular free wall volume and $\mathrm{PaO}_{2}$ or the right ventricular ejection fraction, measured by radionuclide ventriculography. Assessment of the right ventricle by magnetic resonance imaging may help to better define patients with cor pulmonale and assess the long term effects of treatment in such patients.
\end{abstract}

Cor pulmonale is defined as right ventricular hypertrophy secondary to diseases that affect either the structure or the function of the lungs. ${ }^{1}$ Only one third of patients with cor pulmonale will be alive four years after the onset of the disease, compared with $64 \%$ of those without cor pulmonale. There has been little change in the survival of patients with this condition over the past 25 years. ${ }^{23}$

In view of the diagnostic importance of right ventricular hypertrophy, many noninvasive techniques have been used to measure right ventricular dimensions, including electrocardiography, ${ }^{4}$ echocardiography, ${ }^{56}$ and thallium-201 perfusion scanning. ${ }^{7}$ At present, however, accurate, quantitative assessment of right ventricular hypertrophy requires pathological confirmation. There is therefore a need to develop a non-invasive and easily repeatable technique to measure right ventricular hypertrophy to define cor pulmonale more accurately in life and to study the effects of treatment in patients with chronic obstructive lung disease. ${ }^{8-10}$

Magnetic resonance imaging has two important attributes that make it suitable for imaging the cardiovascular system. Firstly, the natural contrast between blood and cardiac tissue allows accurate assessment of both the ventricular wall and the size of the chambers. $^{11}$ Secondly, the technique allows tomographic imaging in a plane orthogonal to the interventricular septum. In this study we have used quantitative magnetic resonance imaging to measure right ventricular wall and chamber volume in normal subjects and patients with chronic obstructive lung disease, and have correlated the results with measurements of pulmonary haemodynamics in the patients.

\section{Methods}

SUBJECTS

Four healthy young non-smoking subjects with no clinical evidence of cardiovascular or respiratory diseases (one women and three men, aged 30-38 years) and five normal older subjects (four women and one man, aged 6379 years) underwent magnetic resonance imaging. The four younger subjects had the investigation on three separate occasions.

We studied 16 patients (seven women and nine men) with chronic obstructive lung disease, whose mean age was $65 \cdot 4$ (range $40-80$ ) years. All the patients had chronic, largely irreversible, airflow limitation (mean $\mathrm{FEV}_{1}$ 0.73 , range $0.3-1.41$; mean FVC 2.4 , range $0.9-4.0 \mathrm{l}$ ) and were hypoxaemic (mean arterial oxygen tension $\left(\mathrm{PaO}_{2}\right) 6 \cdot 5$, range $4 \cdot 9-8 \cdot 3 \mathrm{kPa}$, and most were also hypercapnic (mean carbon dioxide tension $\left(\mathrm{PaCO}_{2}\right)$ 6.5, range $4 \cdot 9-8 \cdot 8$ $\mathrm{kPa}$ ). The patients were clinically stable when studied. None had evidence of peripheral oedema, and their arterial blood gas values, $\mathrm{FEV}_{1}$, and body weight were stable during the six weeks before the study.

\section{PULMONARY HAEMODYNAMICS}

Right heart catheterisation was carried out as part of the routine assessment for long term domiciliary oxygen therapy. Right heart catheterisation was performed via a right antecubital fossa vein with a 7F Swan-Ganz catheter under local anaesthesia and without 

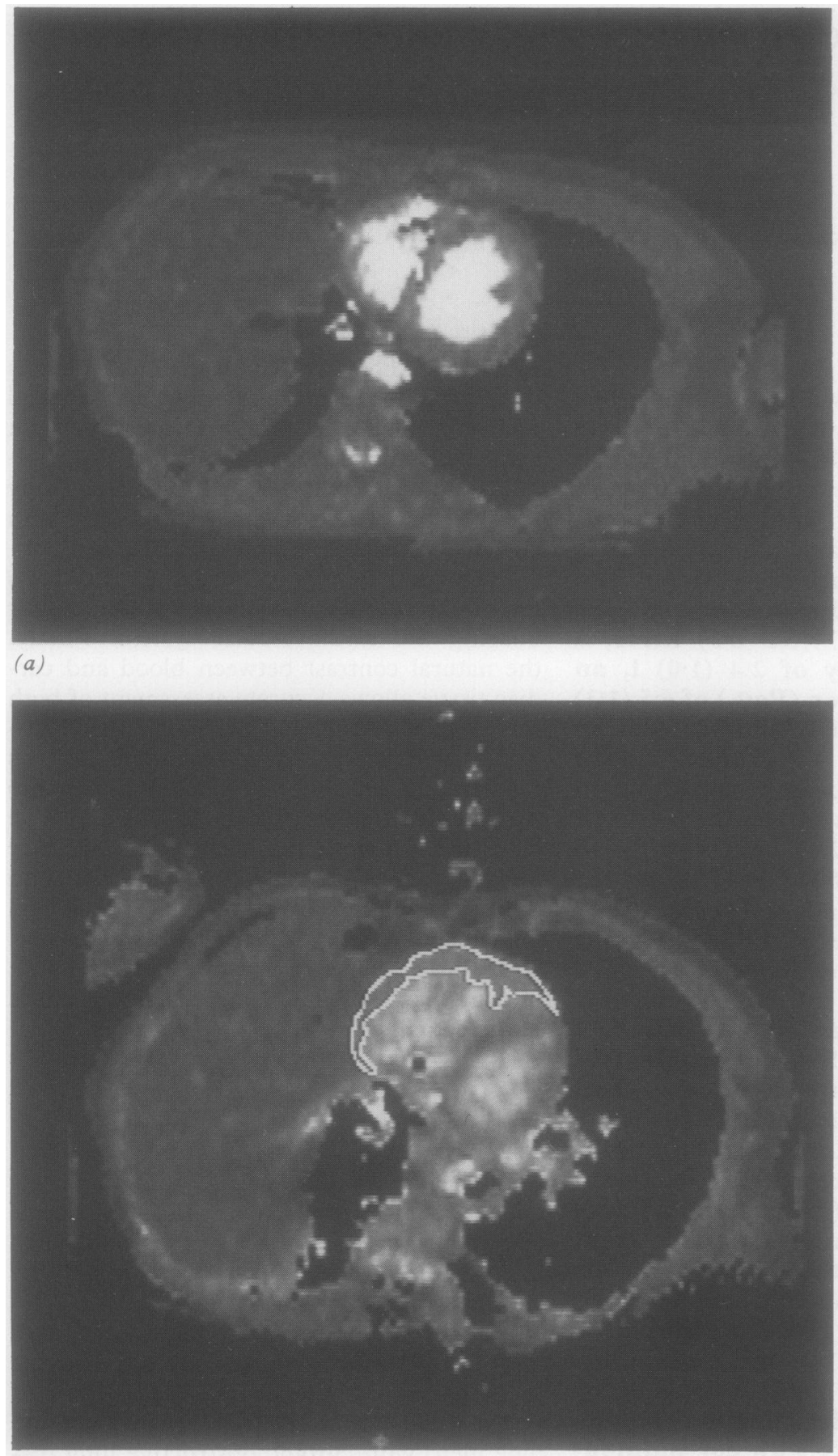

Figure 1 Two $T$, maps of angled transverse sections obtained at the level of the ventricles in (a) a normal subject and (b) a patient with right ventricular hypertrophy and dilatation. In (b) the right ventricular free wall is outlined in white.

premedication. Pressures were measured while the patients were semisupine at $45^{\circ}$. They were zero referenced to a point $5 \mathrm{~cm}$ below the sternal notch and averaged over three respiratory cycles; mean pressures were obtained by electrical integration. Cardiac output was measured by the thermodilution technique. The mean of three values that varied by less than $10 \%$ was used in the analysis. During the cardiac catheterisation the right ventricular ejection fraction was measured by gated equilibrium radionuclide ventriculography. ${ }^{12}$

MAGNETIC RESONANCE IMAGING

Magnetic resonance imaging was carried out two to five days after the cardiac catheterisa- tion, a low field system being used that operated at 0.08 Tesla ( $M$ and $D$ Technology). A cardiac gating technique was used with two non-ferromagnetic electrodes placed on the left anterior chest wall and right wrist. The peak of the $R$ wave was used to trigger data acquisition during end systole $(210 \mathrm{~ms}$ after the upstroke $R$ wave). Scout images were obtained in a coronal plane to visualise the ventricles in the longitudinal axis. Transverse images were then aligned so that the imaging plane was perpendicular to the interventricular septum. Eight slices $16 \mathrm{~mm}$ thick were acquired to encompass the ventricles from base to apex, but to exclude the ventricular outflow tracts. An interleaved saturation recovery-inversion recovery pulse sequence $\left(T_{1}=100 \mathrm{~ms}\right.$, interslice $T_{R}=42 \mathrm{~ms}, T_{E}=22$ ms) was used, from which a map of the relaxation parameter $T_{1}$ was calculated. ${ }^{13}$ The $T_{1}$ map image showed good contrast between the myocardium and the epicardial fat. The outline of the endocardial and epicardial interfaces was defined as an irregular region of interest. The right ventricular free wall area excluding the interventricular septum, the left ventricular wall area including the interventricular septum, and both ventricular chamber areas were measured separately on all images. These values were then multiplied by the slice thickness and summated to obtain the chamber and wall volumes. Images were acquired on a $128 \times 64$ matrix with a field of view of $384 \mathrm{~mm}$. Each examination lasted about 40 minutes. Examples of the images obtained in a normal subject and a patient with right ventricular hypertrophy and dilatation are shown in figure 1 .

To determine the intraobserver and interobserver variability measurements were made on each image on three separate occasions by the same observer (LWT) and independently by a second observer (HMcR), without knowledge of the other's results. The mean values were used in the correlations.

Values were compared by means of the paired Student's $t$ test. Correlation coefficients were obtained by linear regression analysis.

\section{Results}

REPRODUCIBILITY

The interobserver variability for measurements of right ventricular volume was $14 \%$, and the intraobserver variability was $6 \%$ for LWT and $7 \%$ for HMcR. With a perspex phantom, containing cubes of known dimensions filled with copper sulphate solution, the accuracy of linear measurements on the $T_{1}$ map images was within $\pm 5 \%$.

The right ventricular free wall volume in young healthy subjects was 28.5 (range 20.7$35 \cdot 6) \mathrm{cm}^{3}$, compared with $20 \cdot 8$ (range $9 \cdot 1-31 \cdot 7$ ) $\mathrm{cm}^{3}$ in the healthy older volunteers. The mean percentage difference in the measurement of right ventricular free wall volume measured from images acquired on three separate occasions in the four younger subjects was $3.0 \%$ (range $1 \cdot 1-7 \cdot 0 \%$ ). 
Correlations between right ventricular free wall and chamber volumes and pulmonary haemodynamic data in 16 patients with chronic bronchitis and emphysema

\begin{tabular}{|c|c|c|c|c|}
\hline & \multicolumn{2}{|c|}{ Free wall volume } & \multicolumn{2}{|c|}{ End systolic chamber volume } \\
\hline & $r$ & $p$ & $r$ & $p$ \\
\hline Systolic pulmonary arterial pressure & 0.74 & $<0.01$ & 0.47 & NS \\
\hline Mean pulmonary arterial pressure & 0.72 & $<0.01$ & $0 \cdot 50$ & $<0.05$ \\
\hline Pulmonary vascular resistance & 0.65 & $<0.01$ & 0.32 & NS \\
\hline $\mathrm{PaCO}_{2}$ & 0.56 & $<0.02$ & $0 \cdot 23$ & NS \\
\hline $\mathrm{PaO}_{2}$ & $-0 \cdot 25$ & NS & -0.37 & NS \\
\hline RV end systolic chamber volume & 0.71 & $<0.01$ & & - \\
\hline LV end systolic chamber volume & $0 \cdot 19$ & NS & -0.03 & NS \\
\hline Radionuclide $R V$ ejection fraction & -0.09 & NS & $-0 \cdot 19$ & NS \\
\hline
\end{tabular}

$\mathrm{PaCO}_{2}$-arterial carbon dioxide tension; $\mathrm{PaO}_{2}$-arterial oxygen tension; $\mathrm{RV}$-right ventricular; $L V$-left ventricular.

\section{Discussion}

This study has shown that estimates of right ventricular wall volume measured by magnetic resonance imaging in patients with chronic obstructive lung disease correlate with pulmonary arterial pressure and resistance (figs 2 and 3). The technique can be used to measure right ventricular hypertrophy according to the World Health Organisation definition of cor pulmonale. $^{2}$

The magnetic resonance imaging equipment available to us is a low field system, which is by no means ideal. Higher field systems and the use of a spin echo pulse sequence technique, which was not available when the study was initiated, would undoubtedly improve resolution. Even so, the images we obtained were adequate for this study.

The method we describe has a good intraobserver variability. The poorer interobserver variability reflects the degree of subjectivity in outlining the right ventricular wall. Our technique for measuring right ventricular wall volume was reproducible when this was measured in the same individual on three separate occasions despite inevitable changes in the position of the subject. A wide variation in the values for right ventricular weight $(103 \pm$ $35 \mathrm{mg}$ ) is found in patients with chronic obstructive lung disease and respiratory failure. ${ }^{14}$

Other techniques, such as subxiphoid echocardiography, have been used to measure right ventricular wall thickness, though it is often impossible to obtain a satisfactory view of the ventricle in patients with chronic obstructive lung disease. ${ }^{1516}$ In addition, the measurements are usually made from a limited number of points on the right ventricular free wall. Measurements of right ventricular wall thickness have been made recently from multiple points on the free wall with magnetic resonance imaging and have been shown to correlate with the echocardiographic findings. ${ }^{17}$ Nevertheless, measurements of right ventricular wall thickness have important limitations in monitoring sequential changes. Firstly, small variations in wall thickness are

PVR

(dyne.

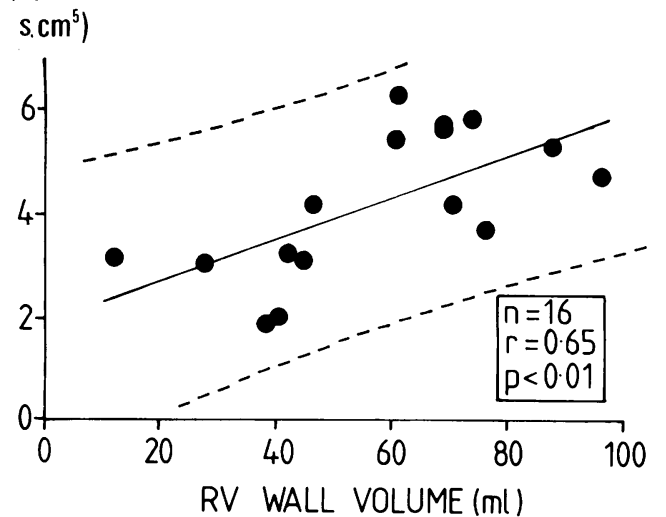

Figure 3 Correlation between the right ventricular $(R V)$ free wall volume and the pulmonary vascular resistance (PVR).
Figure 2 Correlation between the right ventricular $(R V)$ free wall volume and the systolic pulmonary arterial pressure $(P A P)$. 
difficult to detect and may be due to alterations in the position or obliquity of the scan. Secondly, changes that result in ventricular dilatation may alter the right ventricular wall thickness. Many necropsy studies have shown that right ventricular wall thickness correlates poorly with right ventricular weight and should not be considered a good indicator of right ventricular hypertrophy. ${ }^{18-22}$

These considerations led us to develop a method to measure right ventricular wall volume using magnetic resonance imaging. Previous studies have already shown that this is capable of providing accurate information on the left ventricular wall and chamber dimensions. ${ }^{1323}$ As magnetic resonance imaging is essentially a three dimensional imaging process its accuracy does not depend on geometric models to calculate ventricular dimensions as with other techniques, such as biplane angiography or echocardiography. ${ }^{24-26}$ Thus magnetic resonance imaging is particularly useful for measurement of right ventricular volumes because of the complex and variable shape of this chamber, even in normal subjects. ${ }^{24}$ The right ventricle was imaged clearly in all our patients, although Suzuki et $a l^{17}$ recently reported clear visualisation of only $68 \%$ of the length of the free wall of the right ventricle in normal subjects with magnetic resonance imaging. Several factors may explain this discrepancy. In our study all the images were acquired during end systole and not in end diastole. We used angled transaxial images, in contrast to the short axis images in the paraxial plane used in the study by Suzuki et al. ${ }^{17}$ Additionally, all of our patients had hyperinflated lungs, with an increase in the size of the retrosternal air space, which aided the distinction between the right ventricular wall and the retrosternal tissues.

At present there is no generally agreed gold standard for measurement of right ventricular chamber volumes in either normal subjects or patients with cor pulmonale, though magnetic resonance imaging probably yields the best results. ${ }^{23}$ Data from normal volunteers derived from biplane angiography have produced right ventricular end systolic chamber volumes of 39 (9) $\mathrm{ml}^{24}$ and $26(6) \mathrm{ml}^{25}$ whereas the end systolic chamber volumes in the right ventricle determined by magnetic resonance imaging have ranged from 43 to $72 \mathrm{ml} .{ }^{23}$ The right ventricular end systolic chamber volumes in our patients were within this range. This finding was not unexpected as none of our patients had any features of right ventricular failure at the time of the study. We have previously found relatively normal values for right ventricular end systolic volume in a similar group of patients with chronic obstructive lung disease, determining chamber volume by radionuclide ventriculography and combining measurements of stroke volume and right ventricular ejection fraction. ${ }^{27} 28$

All our patients who had systolic pulmonary arterial pressures above $40 \mathrm{~mm} \mathrm{Hg}$ had right ventricular wall volumes above the range seen in normal subjects; but some patients with lower pulmonary artery pressures $(\leqslant 40 \mathrm{~mm}$
$\mathrm{Hg}$ ) had values outside the normal range. Some of the scatter in the correlation between right ventricular wall volume and pulmonary arterial pressure may reflect variation between patients in the duration of pulmonary hypertension.

The right ventricular end systolic volume measured by magnetic resonance imaging, as in this study, underestimates the true right ventricular chamber volume. This is because we chose to exclude the right ventricular outflow tract, as the pulmonary valve could not be accurately delineated within the outflow tract in most patients. The contribution that the right ventricular outflow tract makes to the right ventricular chamber volume will vary in patients with and without pulmonary hypertension. As the outflow tract contains little muscle, however, this should not alter the right ventricular wall volume appreciably. The measurements of the left ventricular end systolic chamber volume made by magnetic resonance imaging in our patients with chronic obstructive lung disease are similar to those made by Longmore et al in normal subjects with magnetic resonance imaging. ${ }^{23}$ None' of the patients we studied had overt evidence of left ventricular disease, and there was no correlation between the left and right ventricular wall volumes. The association of left ventricular hypertrophy with chronic obstructive lung disease is controversial. Although some studies have shown left ventricular hypertrophy in such patients, ${ }^{2930}$ at least one report has shown that left ventricular weight decreased in patients with severe emphysema. ${ }^{31}$

In our study right ventricular end systolic chamber volume increased as the right ventricle showed more hypertrophy, but the correlation between chamber volume and pulmonary arterial pressure was weak (table). This confirms our previous finding ${ }^{28}$ and indicates that, despite the presence of pulmonary arterial hypertension in these patients, the right ventricular end systolic volume remains relatively normal, suggesting well preserved right ventricular function. ${ }^{1228}$ Interestingly, there was no significant correlation between right ventricular function, as assessed by the right ventricular ejection fraction, and the degree of right ventricular hypertrophy measured by magnetic resonance imaging. Although right ventricular free wall volume was correlated with pulmonary arterial pressure, this relationship was not sufficiently strong for an accurate non-invasive measurement of pulmonary arterial pressure to be based on magnetic resonance imaging. As the pulmonary arterial pressure is not a true measure of ventricular afterload and, as discussed above, the duration of pulmonary hypertension is likely to differ between patients, the lack of a strong relation between pulmonary arterial pressure and right ventricular wall volume is not unexpected.

We found no correlation between right ventricular free wall volume and $\mathrm{PaO}_{2}$, perhaps because of the narrow range of $\mathrm{PaO}_{2}$ in these patients. Previous data have suggested a relation between right ventricular hypertrophy and $\mathrm{PaCO}_{2}{ }^{32}$ Our study confirms a weak correlation between these variables. 
In summary, this study has shown that magnetic resonance imaging can be used to obtain volumetric data from the right ventricle in patients with chronic obstructive lung disease, and that this correlates with pulmonary artery pressure. This is a non-invasive, repeatable, and safe technique that could undoubtedly be improved with a higher field system, which would allow the effect of therapeutic interventions on right ventricular volumes to be assessed more accurately. The results of our study suggest that assessment of the right ventricle by magnetic resonance imaging in patients with chronic obstructive lung disease merits further study, with pathological verification of the results.

We wish to thank Mrs R H B Douglas and Mrs A Blane for their technical assistance and Mrs C Hendrie for typing the manuscript.

1 World Health Organisation. Chronic cor pulmonale. A report of the expert committee. Circulation 1963;27: 594-8.

2 Renzetti AD, McClement JH, Litt BD. The veterans administration co-operative study of pulmonary function. III: Mortality in relation to respiratory function in chronic obstructive lung disease. $\mathrm{Am} J \mathrm{~J}$ Med 1966;41:115-9.

3 France AJ, Prescott RJ, Biernacki W, Muir AL, MacNee W. Does right ventricular function predict survival in patients with chronic obstructive pulmonary disease? Thorax 1988;43:621-6.

4 Padmavati S, Raizada V. Electrocardiogram in chronic cor pulmonale. Br Heart $J$ 1972;34:658-67.

5 Prakash R. Determination of right ventricular wall thickness in systole and diastole. Echocardiographic and necropsy correlation in 32 patients. Br Heart $J$ 1978;40:1257-61.

6 Foale $R$, Nihoyannopoulos P, McKenna W, et al. Echocardiographic measurement of the normal adult right ventricle. Br Heart $J$ 1986;56:33-44.

7 Weitzenblum E, Moyes B, Dickele MC, Methlin G. Delection of right ventricular pressure overloading by thallium-201 myocardial scintigraphy. Chest 1984;85: $164-9$.

8 Leach E, Howard P, Barer GR. Resolution of hypoxic changes in the heart and pulmonary arteries of rats during intermittent correction of hypoxia. Clin Sci Mol Med 1977;52:153-62.

9 Timms RM, Khaja FU, Williams GW, and the Nocturnal Oxygen Therapy Trial Group. Haemodynamic response to oxygen therapy in chronic obstructive pulmonary disease. Ann Intern Med 1985;102:29-36.

10 Howard P. Drugs or oxygen for hypoxic cor pulmonale? $\mathrm{Br}$ Med J 1983;287:1159-60.

11 Longmore DB, Klipstein RH, Underwood SR, et al. Dimensional accuracy of magnetic resonance in studies of the heart. Lancet 1988;i:1360-2.
12 MacNee W, Xue QF, Hannan WJ, et al. Assessment by radionuclide angiography of right and left ventricular function in chronic bronchitis and emphysema. Thorax 1983;38:494-500.

13 Smith MA, Ridgway JP, Brydon JWE, et al. ECG-gated T1 images of the heart. Phys Med Biol 1986;3:771-8.

14 Calverley PMA, Lamb D, Flenley DC. Pathological correlations in hypoxic cor pulmonale [abstract]. Am Rev Respir Dis 1988;137(suppl):A180.

15 Matsukubo HT, Matsuura N, Endo J, et al. Echocardiographic measurement of right ventricular wall Echocardiographic measurement of right ventricular wall
thickness: a new approach of subxiphoid-echocardiothickness: a new approach of su
graphy. Circulation 1977;56:278-89.

16 Weitzenblum E, Zielinski E, Bishop JM. The diagnosis of cor pulmonale by non-invasive methods: a challenge for the pulmonologist and cardiologist. Bull Eur Physiopathol Respir 1983;19:423-6.

17 Suzuki J, Sakamoto T, Takenaka K, et al. Assessment of the thickness of the right ventricular free wall by magnetic resonance imaging in patients with hypertrophic carciomyopathy. Br Heart $J$ 1988;60:440-5.

18 Mitchell RS, Stanford RE, Silvers GW, Dart G. The right ventricle in chronic airway obstruction: a clinical-pathological study. Am Rev Respir Dis 1976;277:947-9.

$19 \mathrm{Lamb} \mathrm{D}$. Heart weight and assessment of ventricular hypertrophy. In: Dyke SC, ed. Recent advances in clinical pathology. Series 6. London: Churchill Livingstone, 1973:133-48.

20 Fulton RM, Hutchison EC, Jones AM. Ventricular weight in cardiac hypertrophy. Br Heart $J$ 1952;14:413-20.

21 Astorri E, Chizzola A, Visioli A, et al. Right ventricular hypertrophy: a cytometric study on 55 human hearts. J Mol Cell Cardiol 1971;2:99.

22 Reiner L, Mazzoleni A, Rodriquez FL, Fredenthal RR. The weight of the human heart. Arch Pathol 1959;68:58-73.

23 Longmore DB, Underwood SR, Hounsfield GN, et al. Dimensional accuracy of magnetic resonance in studies of the heart. Lancet 1985;i:1360-2.

24 Arcilla RA, Tsai P, Thilenus O, Ranniger K. Angiographic method for volume estimation of the right and left ventricles. Chest 1971;60:446-54.

25 Gentzler D, Briselli MF, Gault JH. Angiographic estimation of right ventricular volume in man. Circulation 1974;50:324-30.

26 Ferlinz J. Measurements of right ventricular volumes in man from single plane cineangiograms. A comparison to the from single plane cineangiograms. A com

27 MacNee W, Wathen CG, Flenley DC, Muir AL. The effects of controlled oxygen therapy on ventricular function in patients with stable and decompensated cor pulmonale. Am Rev Respir Dis 1988;137:1289-95.

28 Biernacki W, Flenley DC, Muir AL, MacNee W. The effect of pulmonary hypertension on right ventricular function in patients with chronic obstructive pulmonary disease. Chest 1988;94:1169-75.

29 Michelson N. Bilateral ventricular hypertrophy due to chronic pulmonary disease. Dis Chest 1980;38:435-46.

30 Murphy ML, Adamson J, Hutcheson F. Left ventricular hypertrophy in patients with chronic bronchitis and hypertrophy in patients with chronic bronchit

31 Foraker AG, Bedrossian CWM, Anderson AE Jr. Myocardial dimensions and proportions in pulmonary emphysema. Arch Pathol 1970;90:344.

32 Aber GM, Bayley TJ, Bishop JM. Interrelationships between renal and cardiac function and respiratory gas exchange in obstructive airways disease. Clin Sci 1963;25:159-70. 